Research Article

\title{
Replacement of Cable Stays in Yonghe Bridge in Tianjin, China
}

\author{
Hongjiang Li $\mathbb{D}$ \\ Research Institute of Highway, Ministry of Transport, 8 Xitucheng Rd., Haidian District, Beijing 100088, China \\ Correspondence should be addressed to Hongjiang Li; hongjiangli.rioh@gmail.com
}

Received 20 October 2020; Revised 7 December 2020; Accepted 10 December 2020; Published 18 December 2020

Academic Editor: Xueping Fan

Copyright $(2020$ Hongjiang Li. This is an open access article distributed under the Creative Commons Attribution License, which permits unrestricted use, distribution, and reproduction in any medium, provided the original work is properly cited.

\begin{abstract}
Cable replacement is one of the most important approaches for retrofitting an existing cable-stayed bridge. The Yonghe Bridge opened to traffic in 1987 and was the largest concrete cable-stayed bridge in Asia at the time. After nearly 20 years in service, its stay-cable system was completely replaced. The present paper details the key technical points of cable replacement in this bridge, including causes of replacement, cable replacement design, construction monitoring during replacement, and cable tension tuning after replacement. Based on the measurements during construction, the variation in structural condition indexes was thoroughly investigated, such as cable forces throughout the bridge, geometry profile of bridge deck, and tower horizontal displacements. The structural changes due to cable replacement were evaluated, and then, a relatively desirable scheme of cable adjustment was correspondingly put forward. The measured results showed that, influenced by the accumulated tolerances of cable forces during construction, cable replacement may often lead to a further deviation of structural condition. In this instance, cable adjustment is an effective compensation measure to improve the overall structural condition of the bridge. The practice of cable replacement in the Yonghe Bridge has provided some valuable experience or beneficial references for the similar retrofitting cases.
\end{abstract}

\section{Introduction}

Concrete cable-stayed bridge is a relatively economical structural type among those with a main span of $200 \mathrm{~m}$ to $500 \mathrm{~m}$ [1]. Since the Maracaibo Lake Bridge in Venezuela was completed in 1962, concrete cable-stayed bridge has developed for more than half a century. In the last three decades or more, many distinctive and prestigious concrete cable-stayed bridges have been successively built all over the world $[2,3]$, demonstrating that a rapid development both in span scale and construction technology has occurred in this type of structure. However, it should be cautiously noted that the reliability of these bridges has been continuously challenged in the running period. The potential for structural safety and durability problems has received more and more concerns. The continuous accumulation of damage in structural components often causes the internal force redistribution throughout the entire structure, which is the result of structural condition deviation from the originally completed bridge. Especially, some local structural members, represented by stay cables, fail to work prematurely with incapability of reaching their design service life. The damage or deterioration occurring frequently during the operation period has led to significantly increasing maintenance costs in many countries, which has heavily influenced the economy of concrete cable-stayed bridge.

Thus, retrofitting of concrete cable-stayed bridges in service has increasingly become an urgent and worldwide issue. Routinely, the alternative methods include external bonding techniques, external prestressing, enlarging cross sections, cable tension tuning or adjustment, and cable replacement [4-6]. Thereinto, cable replacement is considered as one of the most important approaches to preserve and potentially extend the service life of existing concrete cable-stayed bridges [7]. Obviously, the substantial reduction in the service life of stay cables is fundamentally responsible for cable replacement in a concrete cable-stayed bridge while in service.

The present study systematically introduces the details of cable replacement in the Yonghe Bridge in Tianjin, China, including the reasons for replacement, the replacement design and construction monitoring during replacement, and the structural condition improvement after replacement 
by cable tension tuning. Also, it focuses on the analysis of variation in three structural indexes under the full final dead load, i.e., vertical profile of the bridge deck, tower horizontal displacements, and cable forces throughout the bridge. The Yonghe Bridge is a representative of early concrete cablestayed bridges in China and has been paid much attention by bridge engineers and scholars at home and abroad for a long time. The objective of this paper is to present the procedure and results of cable replacement in this bridge and then to provide possible successful experience and future improvements for similar retrofitting cases.

\section{Bridge Description}

The Yonghe Bridge is located on Jin-Han Highway connecting Tianjin and Hangu over the Yongding New River in China (see Figure 1). It is a five-span cable-stayed bridge, with a continuous and floatable prestressed concrete (PC) main girder, double pylons, and double cable planes. The center (or main) span is $260 \mathrm{~m}$ long, and the two side spans on each side (south and north) are $25.15 \mathrm{~m}$ and $99.85 \mathrm{~m}$ long, as shown in Figure 2(a). Each pylon or tower is a modified $\mathrm{H}$-shape (Figure 2(b)), with a height of $55.5 \mathrm{~m}$, and is fixed with the main pier ( $P 2$ or $P 3)$. The main piers are cast on reinforced concrete caisson foundations, while the other piers ( $P 1$ and $P 4)$ and abutments (A0 and $A 5)$ are cast on a group of reinforced concrete tube piles. Also, P1 or P4 is designed as the auxiliary pier, at which a tension rocker bearing system is installed to resist the negative reaction force possibly occurring in the service stage. Actually, the system is comprised of two short parallel wire cables, with one upstream and the other downstream.

The main girder is designed as a partially PC member, with a total length of $512.4 \mathrm{~m}$. A complex segmental construction procedure is implemented in its erection. Girder segments are precast by match casting and are erected by cantilever splicing at the middle spans and on scaffolding at the side spans. The typical cross section of precast segment is shown in Figure 2(c), which is very similar to that of the Pasco-Kennewick Bridge built in the State of Washington, USA.

The cable stays are arranged in a fan pattern and are grouped by pairs or fours. There are 44 such cable pairs and a total of 176 cables. For convenience, the complete 44 pairs of cable stays are sequentially numbered as $\mathrm{SC} 11^{\prime}-\mathrm{SC} 1^{\prime}$, $\mathrm{SC} 1-\mathrm{SC} 11, \mathrm{NC} 11-\mathrm{NC} 1$, and $\mathrm{NC}^{\prime}{ }^{\prime}-\mathrm{NC} 11^{\prime}$ from the south (Tianjin side) to the north (Hangu side), as shown in Figure 2(a). The main tension elements (MTEs) of these prefabricated stay cables are composed of parallel $5.0 \mathrm{~mm}$ diameter wire bundles consisting of a number of wires varying from 69 to 199 in eight groups. The parallel wire has a typical tensile strength of $1600 \mathrm{MPa}$ and an elastic modulus of $200000 \mathrm{MPa}$.

These wires are arranged in regular hexagon within the cross section of each cable and tightly wrapped with a single $6.0 \mathrm{~mm}$ diameter strand and then encased within highdensity polyethylene (PE) sheathing. In order to improve the antiaging performance of the outer sheathing, carbon black is added into the PE material, and the space between the wires and the PE pipe is filled with cementitious grouting, which is pressure-injected following cable erection on the superstructure.

Hi-Am-type cold-cast sockets are adopted as the staycable anchorage system of the bridge. Figure 3 shows a typical Hi-Am-type socket used in the Yonghe Bridge. A HiAm socket is cylindrical on the outside and conical on the inside. Each wire is anchored to a plate at the end of the socket by a button head. The space in the socket is then filled with epoxy mixed with zinc and small steel balls. Each stay cable has a lower and upper anchorage. The lower socket is anchored under the deck and is usually a fixed end type. The upper socket is anchored at the pylon and is a tensioned end type, or where the cable stressing is carried out by placing shims used for coarse adjustment or turning ring nuts on for finer adjustment.

The erection of the superstructure of the Yonghe Bridge began in October 1984, and the entire bridge was completed and opened to traffic in December 1987. At the time, it was the largest concrete cable-stayed bridge in Asia and the third largest span in the world. However, after approximately 18 years of service, the closure segment at its main span was close to failure, which is the result of a severe opening at the bottom of the wet joint between the cast-in-place closure segment and the adjacent precast segment of the south side [8], as shown in Figure 4. Meanwhile, there was a significant local deflection in the main span. Relative to the originally completed geometric profile, the midspan deflection at its main span could reach $18.8 \mathrm{~cm}$.

From June to October 2006, a novel retrofit technique, called replacement of closure segment (RCS), was put into practice in this bridge $[9,10]$. The original and failed closure segment was successfully removed, and then, a new one was constructed according to its original design. Again, the new closure segment was strengthened by a combined method of enlarging cross sections and unbonded external prestressing, so as to achieve an effective and firm connection between the segments. Subsequently, the deck pavement was refurbished to improve the driving condition. Then, cable replacement was implemented and became an important part of the Retrofitting Project of the Yonghe Bridge implemented in the period from June 2006 to January 2007.

\section{Causes of Cable Replacement}

In the 1980s, stay cables in a concrete cable-stayed bridge are commonly expected to attain a design life of 20-25 years. However, due to corrosion degradation and vibration fatigue attenuation, the actual service life of cable stays is often lower in a considerable number of concrete cable-stayed bridges. According to the statistics of exiting concrete cable-stayed bridges that have undergone cable replacement in China, the actual service life of stay cables is less than 15 years on average, even some bridges implemented complete replacement of cable stays after 6 to 7 years of service [11].

Therefore, almost all the concrete cable-stayed bridges will face the problem of premature cable replacement due to deterioration. The Yonghe Bridge has been in operation for nearly 20 years, from its opening to traffic in 1987 to the 


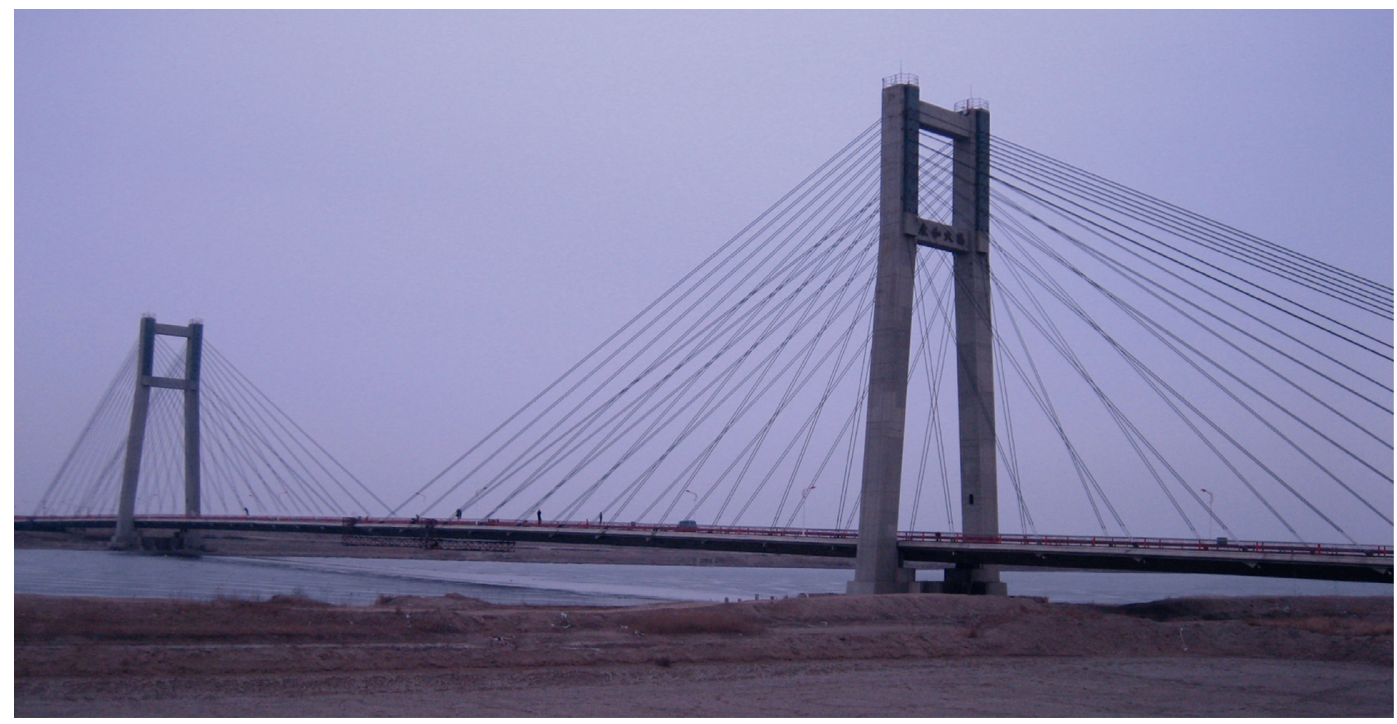

Figure 1: A field photograph of Yonghe Bridge.

completion of the deck pavement refurbishment in 2006. And it was nearly the last concrete cable-stayed bridge built in the same period without undergoing cable replacement in China. Thus, in this sense, approaching the design life is an important reason for cable replacement in the Yonghe Bridge.

Due to the limitations of the production level at that time (1980s) and under the combined action of live loads and various environment factors, the corrosion protection system of cable stays of the Yonghe Bridge was subjected to a severe challenge, which was undoubtedly not optimistic. A field inspection performed in 2005 showed the presence of corrosion within the deck-level anchorage sockets, PE sheathing splits, and rusted stay-cable wires, as shown in Figure 5. So, it is most likely that the MTEs of stay cables have been corroded and degraded, which is another reason for cable replacement in the Yonghe Bridge.

During the replacement construction, a laboratory test on the removed original stay cables was conducted to determine their corrosion conditions and mechanical performances, as listed in Table 1 [12]. The results confirmed that the parallel wires were significantly corroded, which had heavily affected the strength and ductility of cables, and the risk of cable failure or fracture was quite great in the combined action of fatigue and corrosion. Obviously, the strategy of replacing all cable strays presents a wise choice, which not only avoids the occurrence of major structural safety hazard but also reduces the unnecessary economic loss.

\section{Design of Cable Replacement}

4.1. Determination of Tension in New Cable Stays. The structural condition of the Yonghe Bridge before cable replacement has already deviated from that in the originally completed bridge to some extent. In contrast to the geometric profile in originally completed bridge, a noticeable downward deflection occurred at its main span with an observed midspan deflection of $26.4 \mathrm{~cm}$, as shown in Figure 6.

The distribution of cable force increment percentage throughout the bridge is shown in Figure 7. Compared to the condition in the originally completed bridge, the cable forces have varied $-5.1 \%-17.3 \%$, and the summation of tension in all cables increased about 5.1\%.

In addition, the tops of both the south and the north side pylons were observed to sway about $2.8 \mathrm{~cm}$ on average toward the main span.

These structural changes are routinely related to the time-dependent effects in the running period of the bridge, including creep and shrinkage of concrete in towers and main girder, and relaxation of stay cables [13]. However, the increase in superimposed dead load, induced by the refurbishment of bridge deck pavement, is also a very important reason. Although RCS eliminates the hidden danger in structure caused by local failure, it has no significant influence on the overall structural condition, which is usually characterized by cable forces, deck geometric profile, and tower horizontal displacements in a cable-stayed bridge [14].

Therefore, the deviation of structural condition before cable replacement is mainly the result of structural degradation and combined action of various time-dependent factors in the service stage of the bridge. And in actuality, a relatively complete improvement in a structural state has not yet been achieved on the completion of those retrofit measures before cable replacement. Also, unfortunately, the increase in superimposed dead load, caused by the refurbishment of bridge deck pavement, has led to a somewhat unfavorable change in structural state.

Until 2006, the Yonghe Bridge has been in operation for nearly 20 years and has undergone a complex and involved retrofit process during this period. Thus, the structural condition before cable replacement cannot be easily determined, which has brought great difficulties in the determination of the design tensions in new stay cables. The 


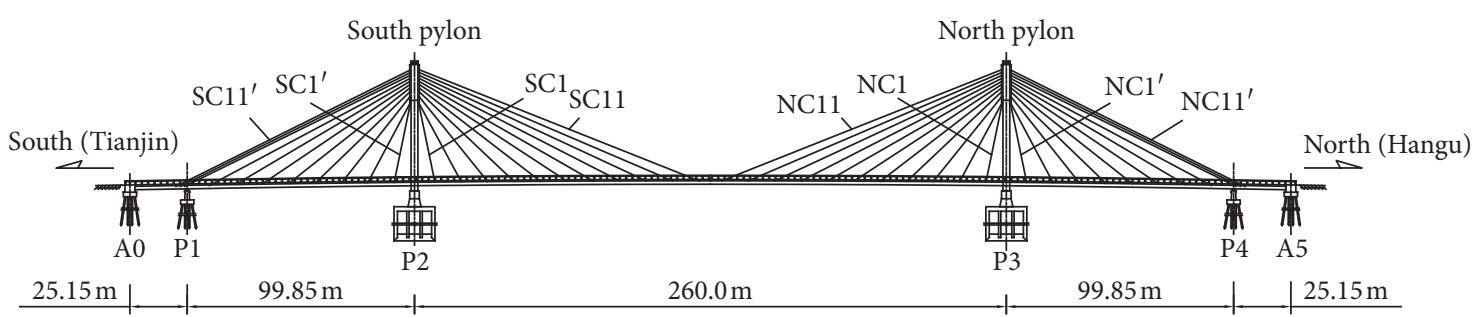

(a)

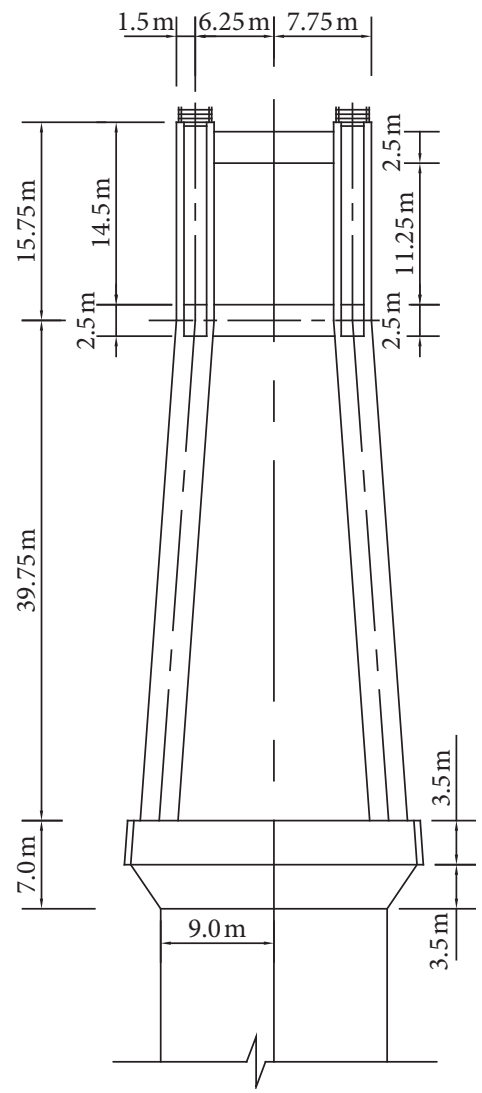

(b)

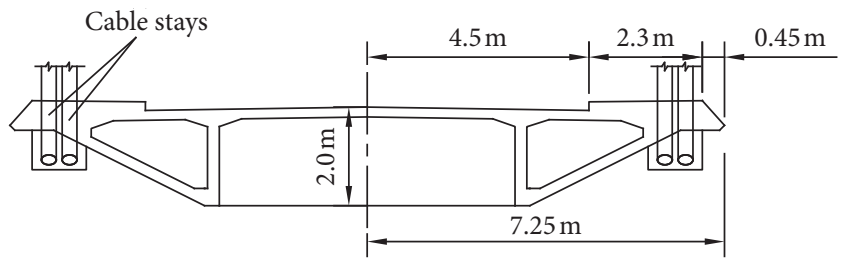

(c)

FIgURE 2: General view of Yonghe Bridge: (a) elevation; (b) side view and details of tower; (c) typical cross section of main girder.

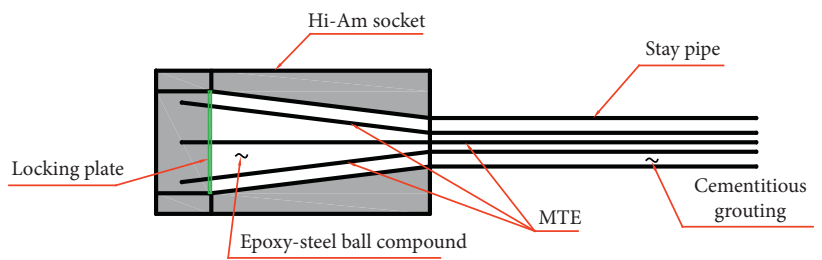

Figure 3: Schematic of Hi-Am socket used in Yonghe Bridge. 


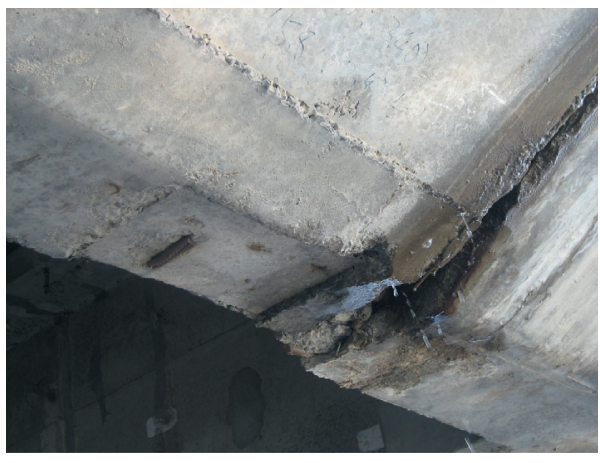

(a)

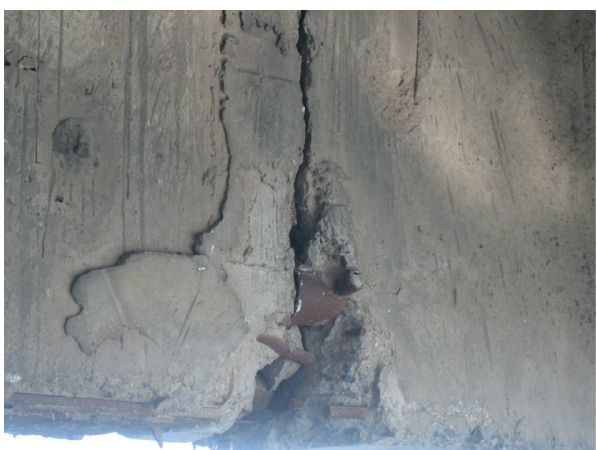

(b)

FIGURE 4: In-site photographs of damage in the closure segment: (a) severe opening at the bottom of the wet joint; (b) fracture of steel bars inside the vertical web of the joint section.

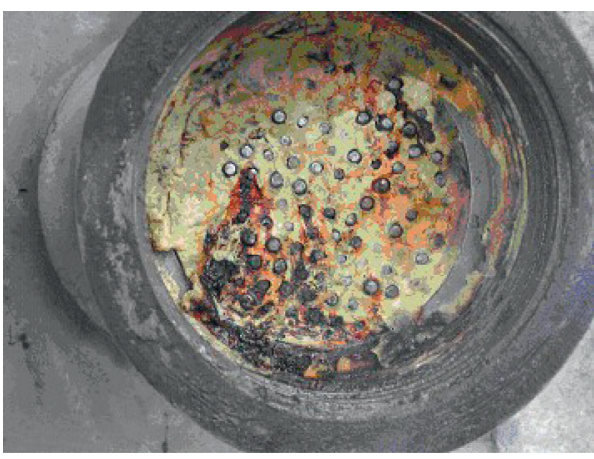

(a)

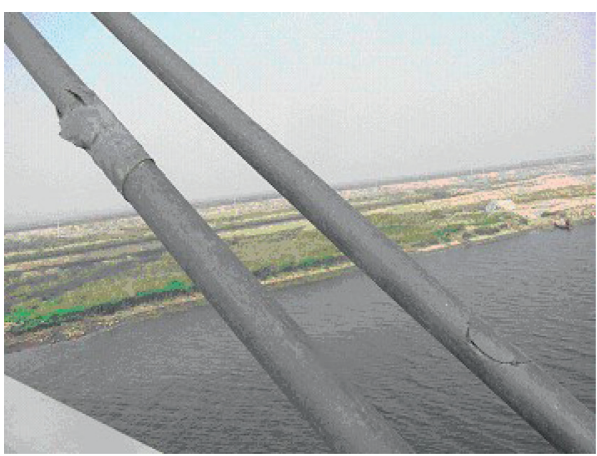

(b)

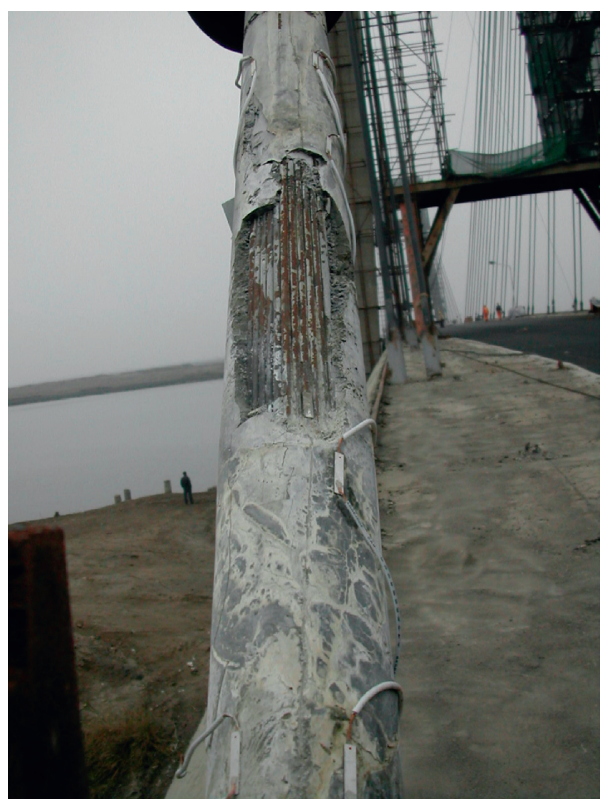

(c)

FIgure 5: Typical defects of cable stays in Yonghe Bridge: (a) corrosion at end plate of one socket with wire button ends; (b) PE sheathing split; (c) corrosion of wires after cutting PE sheathing for the purpose of creating inspection "window."

measured cable forces in the originally completed bridge cannot be directly used as a baseline for cable replacement and can only be considered as a reference for the variation amplitude of new cable forces.
As the structural state of the bridge tends to be very stable with time, the measured cable forces before replacement construction are adopted as the design (or target) pretension forces in new cables so as to avoid the possible 
TABle 1: Laboratory test on the basic mechanical performance of parallel wires in Yonghe Bridge.

\begin{tabular}{lccc}
\hline Performance index & Uncorroded condition & Corroded condition & Percentage of variation $(\%)$ \\
\hline Modulus of elasticity $(\mathrm{MPa})$ & 200400 & 199500 & -0.4 \\
Nominal yield strength $(\mathrm{MPa})$ & 1511.86 & 1446.02 & -4.4 \\
Nominal limit strength $(\mathrm{MPa})$ & 1696.71 & 1621.49 & -4.4 \\
Nominal limit strain $(\mu \varepsilon)$ & 49943.15 & 44397.29 & -11.1 \\
Elongation $(\%)$ & 4.17 & 3.78 & -9.4 \\
\hline
\end{tabular}

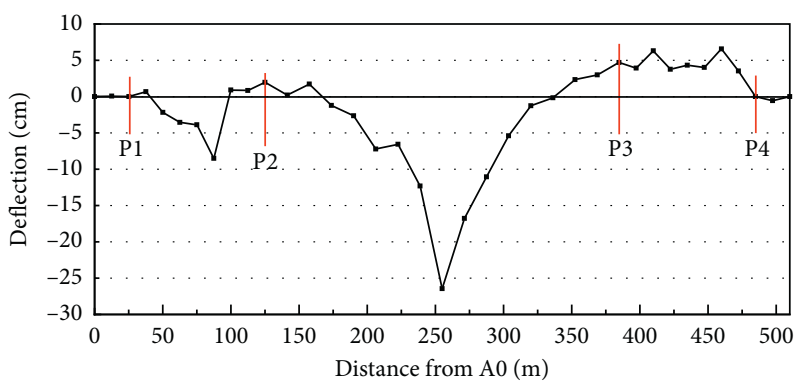

FIgURE 6: Measured deflection of bridge deck before cable replacement.

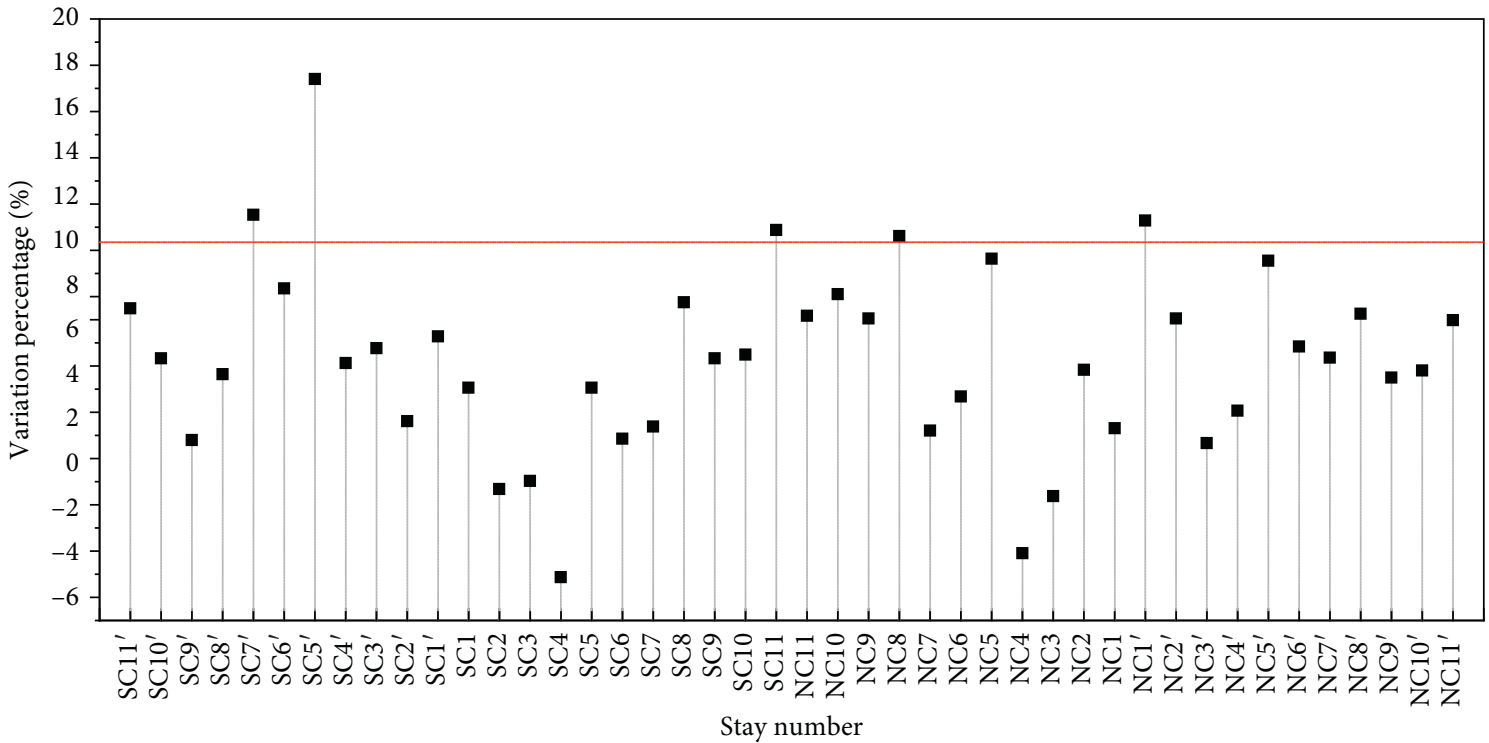

FIgURE 7: Variation percentages of cable forces measured before replacement relative to those in the originally completed bridge.

excessive disturbance in structural state. Then, after the complete replacement of 176 stay cables, the tensions in new cables were adjusted moderately to improve the structural condition of the entire bridge, under the premise of satisfying these cables' minimum safety factor required in its original design of the bridge.

4.2. Performance of New Cable Stays. The replacement cables are being designed for a 30-year design life and incorporated with the latest advancements in corrosion protection and vibration control. The new stay-cable system is comprised of composite anticorrosion-type prefabricated cables with external double helix placed on the surface of the PE pipes to eliminate rain-wind-induced cable vibrations. These cables are typically made of $5.0 \mathrm{~mm}$ high-strength low-relaxation galvanized parallel wires with Hi-Am-type sockets. The lower (located at the girder end) and the upper (located at the pylon end) anchorage are all designed as the tensioned end type, so as to facilitate cable adjustments at any time in the later running period.

Each stay is a twisted cable with extruded sheathing. As the MTE, the steel wires are arranged in a hexagonal shape within the cross section of any stay cable. During the production of each cable, the steel wires are all kept parallel and straight to each other and closely wrapped with external spiral tapes. Then, the anticorrosion grease fills the interstices of the voids between the individual wires to eliminate 
water circulation. Next, the wires are twisted into shape, and the concentric twisted angle is roughly $2-4^{\circ}$ after closed. Finally, the black-color high-density PE protective sheathing, a double-layer sheath with an inner isolation layer, is extruded over the MTE bundle, thus creating a tight fit between the sheathing and MTE.

The number of wires in the replacement cables is the same as that in the original cables and possesses a standard strength of $1670 \mathrm{MPa}(1600 \mathrm{MPa}$ in the original ones). The other technical parameters of stay cables are needed to satisfy the design requirements specified in the relevant codes [15], specifically including modulus of elastic, maximum relaxation rate, nominal breaking load and elongation under static loads, and fatigue performances.

4.3. Replacement Construction Sequence. For convenience, the complete 176 cables of the Yonghe Bridge are redivided into 11 groups. For example, group 11 consists of the cable pairs with the original number of $\mathrm{SC} 11^{\prime}, \mathrm{SC} 11$, $\mathrm{NC} 11$, and $\mathrm{NC}_{11}^{\prime}$, while group 1 includes the cable pairs with the original number of $\mathrm{SC}^{\prime}, \mathrm{SC} 1, \mathrm{NC} 1$, and $\mathrm{NC}^{\prime}$. Thus, each cable grouping is comprised of 16 cables in total. The cable replacement is implemented in the construction sequence from long cables to short ones, and so there are a total of 11 load (or replacement) cases corresponding to 11 cable groupings, respectively. One cable in one pair is replaced at a time on each side of the pylon. In other words, two cables are replaced at a time on each pylon, or four cables are replaced at a time for both pylons. Thus, each load case can be subdivided into 4 replacement construction substeps.

The construction procedure of these 16 cables in each grouping is shown in Figure 8. The labels A, B, C, and D are the construction substeps described above, and the black spot in the figure represents the cables to be removed and then replaced in each substep. It can be seen that the cables to be replaced in each substep is symmetric to each pylon and antisymmetric to the midspan of the main span. And the cables both on the riverside and on the shoreside are replaced synchronously, and the replacement constructions on both towers are also kept pace.

\section{Monitoring of Typical Structural Indexes during Replacement}

In general, the overall structural condition of a cable-stayed bridge can be characterized by cable forces, bridge deck profile, and tower horizontal displacements. Cables forces are checked against targets at every load case, which is of primary importance in replacement construction control. Meanwhile, it is very necessary to investigate the changes in bridge deck profile and tower horizontal displacements. To understand exactly the structural changes and ultimately ensure the attainment of structural safety during construction, the three structural indexes are monitored during the entire process of cable replacement in the Yonghe Bridge.
5.1. Cable Forces. As known to bridge engineers, different (especially adjacent) cable stays interact with each other in a cable-stayed bridge. So, after one stay is replaced, the other stays adjacent to it may also vary significantly in cable force at the same time. Therefore, the tensioning forces in construction are very crucial for the replacement cables to ensure the attainment of predetermined target values (i.e., design pretension forces) at the completion of replacing all the stay cables of the bridge.

The measured pretension forces in stay cables can be routinely obtained by two ways: readings of the hydraulic jacking for tensioning until the ring nut of the cable anchorage system can be just loosened (here called initiating force) and vibration-based force measurement. The former is more direct but may significantly increase on-site operation of cable pull, while the latter is easier to operate in the field with higher efficiency but susceptible to be affected by many factors, including effective length of cable, mass per length, boundary conditions of cable, and bending stiffness of cable [16].

To achieve the effectiveness of cable force monitoring during replacement, the initiating forces of some cable strays are measured before replacement construction in the Yonghe Bridge. One cable in each pair is selected to be measured to obtain the initiating forces. So 44 cables in the entire bridge are measured in total. Meanwhile, the vibration-based measurements are also conducted synchronously in these selected cables, and the results are compared with the initiating forces. When somewhat discrepancy exists between the two ways, the vibration-based measurements are corrected with different coefficients for these 44 cables, respectively. To improve the accuracy of the correction coefficients, this process is repeated at least three times for each selected cable to ensure achieving a good agreement between the vibration-based measurement and the initiating force. The calibrated coefficient for one cable can be used as the other cables in the same pair.

Thereafter, prior to performing the replacement construction of every load case, the tension in the relevant cables (i.e., 16 cables in total) is measured by the vibration-based method. The measured values obtained are adopted as the tensioning forces of the replacement cables in construction. After completion of each load case, the newly replaced 16 cables may be re-stressed to achieve the uniformity of the axial forces in four cables within the same pair, attaining the target pretension forces.

The slightly larger construction loads, along with any traffic loads, are not allowed to pass on the bridge deck during measurement of cable forces and tensioning of new cables; that is, the dead load on the bridge deck remains basically constant. In the view of no significant influence of thermal loads on cable forces [17], the disturbance of environmental temperature on the measurements is not considered specifically in the cable force monitoring. So no special selection was made for cable force monitoring time.

5.2. Bridge Deck Profile. Vertical profile (or deflection) of the bridge deck can be obtained by surveying the as-built elevation of the bridge deck using the precision leveling 


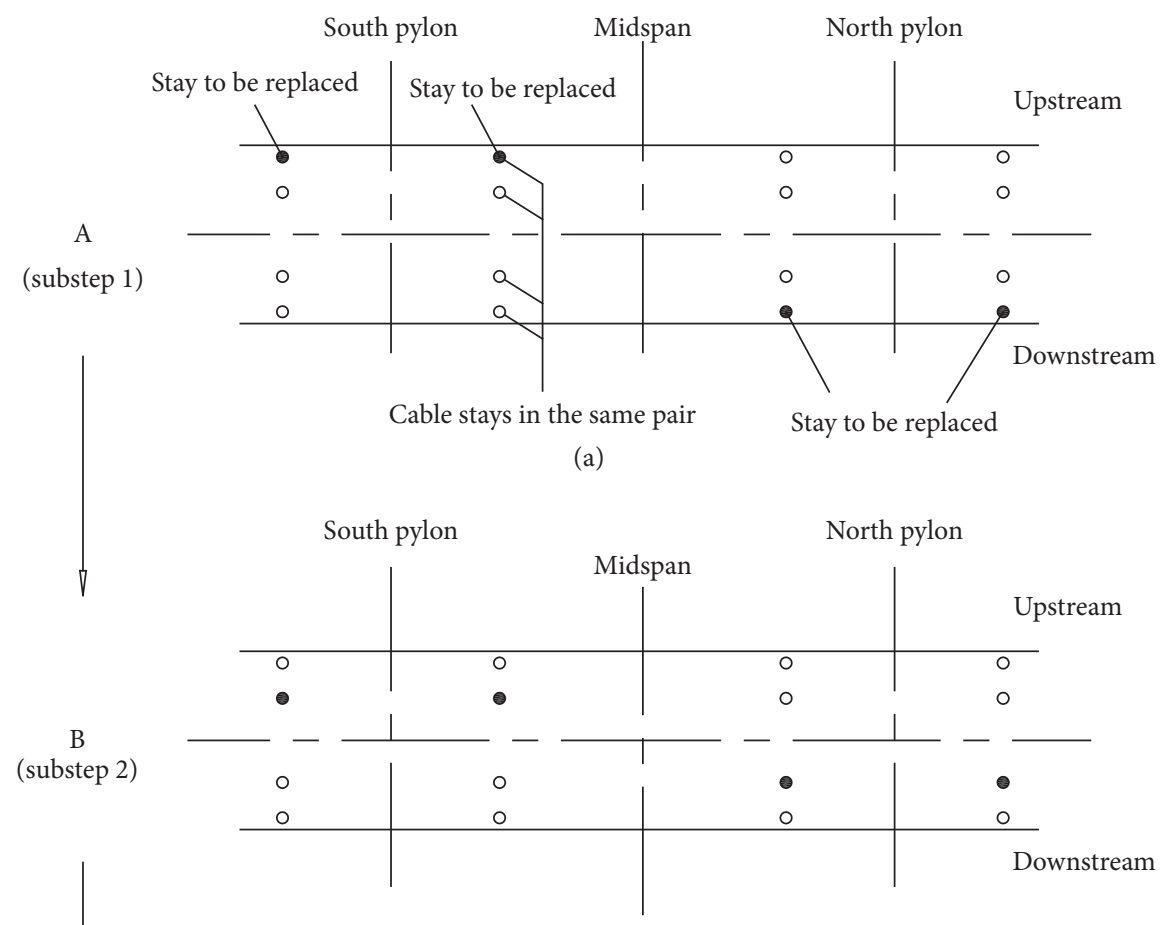

(b)

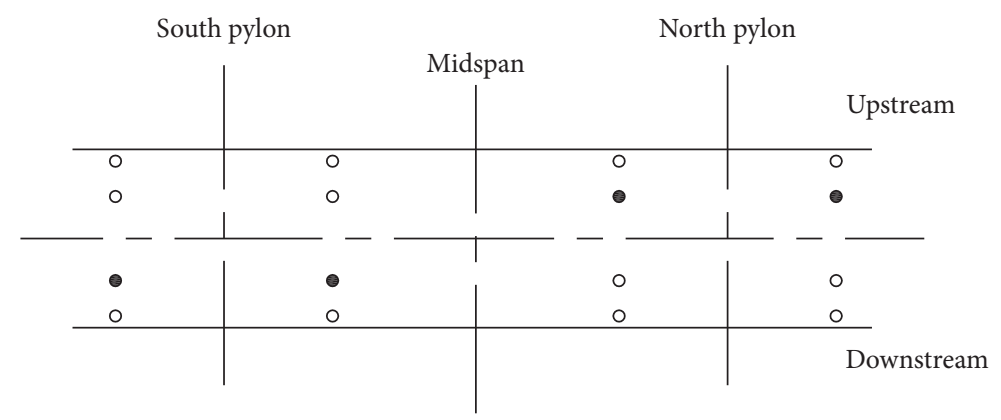

(c)

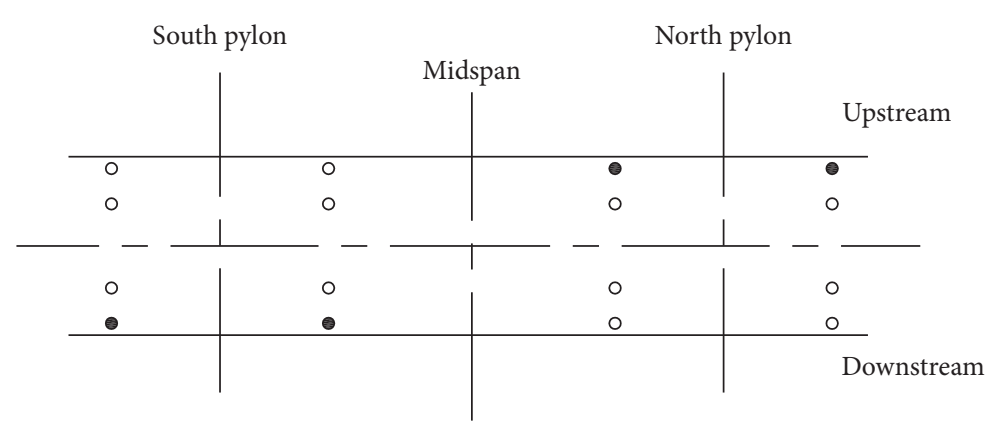

(d)

Figure 8: Schematic of cable replacement construction sequences for each load case.

instruments [18]. The elevation measurement stations, spacing approximately at $1241.5 \mathrm{~cm}$ to $1638.4 \mathrm{~cm}$ along the bridge span length, are arranged at the sidewalk curbs, 37 upstream and 37 downstream, as shown in Figure 9.

In general, various thermal effects, induced by the nonlinear temperature distribution in structure under solar radiation, have a significant influence on the deck profile. It is well understood that the temperature difference between stay cables and concrete main girder or between the sunny and shady sides of each tower and the thermal gradient along the height of concrete main girder are all fallen into the nonlinear temperature distribution. However, the system temperature 


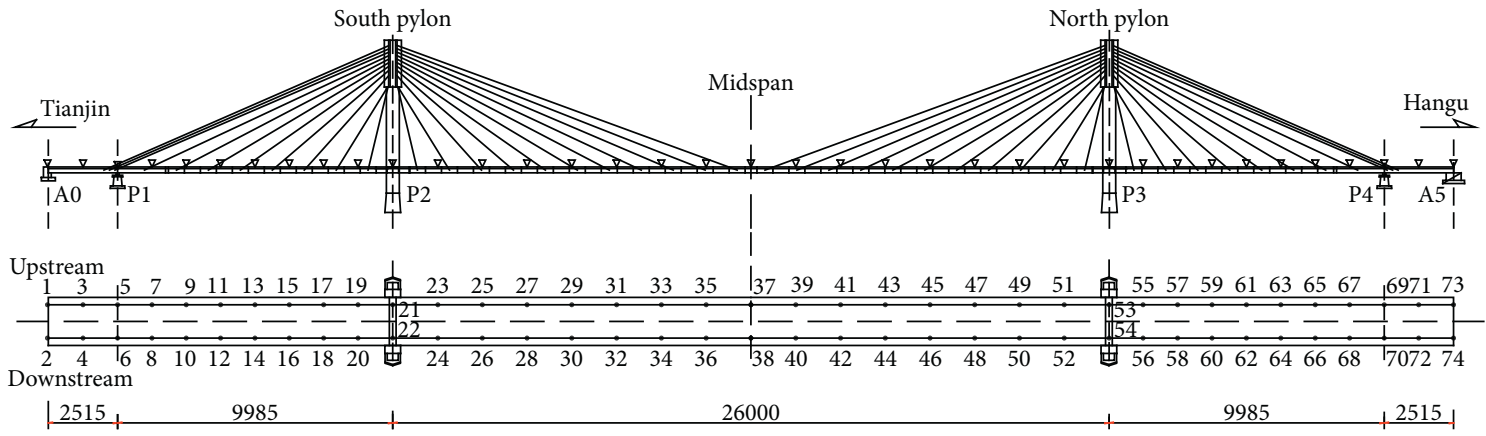

Figure 9: Measurements of bridge deck profile (unit: centimeter).

difference due to seasonal variation, i.e., the temperature rise or reduction of the overall bridge, contributes nonsignificant effect on the bridge deck deflection [17].

Therefore, the surveying period of deck profile during cable replacement of the Yonghe Bridge is selected from 6 : 00 to 8:00 in the morning to avoid the action of solar radiation, without accounting for the system temperature difference effect during the replacement construction.

5.3. Tower Horizontal Displacements. To study the changes in horizontal position atop each pylon during cable replacement, tower horizontal displacements were measured by employing four reflected lenses, which were installed atop both towers in the Yonghe Bridge. Two lenses on one tower were symmetrically located on both sides of upstream and downstream. The data were taken by means of general total stations (GTSs), a type of optoelectronic instruments [18].

Except for the nonlinear temperature distribution described above, the system temperature difference has also a relatively greater effect on tower horizontal displacements. For that reason, the measurement of tower horizontal displacements was carried out in the time interval before sunrise, around 6:00 to 8:00 in the morning. Moreover, the measured data were corrected according by the thermal effect analysis results [17], so as to minimize the system difference effect as far as possible.

\section{Adjustment of Tension in New Cable Stays}

On the completion of complete cable replacement, the pretension forces in the new cable stays varied significantly compared with those before replacement. Figure 10 shows the increment of tension in cable stays after replacement relative to that before replacement. It is estimated that the variation percentages approximately range from $-15.6 \%$ to $15.9 \%$, well beyond the acceptable tolerance range of $\pm 5 \%$ in engineering as usual.

Meanwhile, the local downward deflection near the midspan of the main span is larger than that before replacement, with a deflection increment of about $8.0 \mathrm{~cm}$, as shown in Figure 11. In addition, the tops of both towers continued to incline longitudinally to the main span, varying by $5 \mathrm{~mm}$ and $26 \mathrm{~mm}$, respectively, in comparison with those before replacement.
Thus, it can be seen that cable replacement has caused a greater deviation in structural condition from the originally completed bridge. Obviously, this is the result of the irrationality of the magnitude and distribution of tension in the new cable stays throughout the bridge, which needs to be corrected by cable adjustment. The objectives of adjustment are to control the variation percentage of pretension forces in the new cables relative to the design (or target) values within the range of $\pm 5 \%$ and to take into account the variations in bridge deck profile and tower positions so as to improve the overall structural condition of the bridge.

The scheme of cable tension tuning was developed according by the theoretical calculation results, which are obtained by performing a finite-element analysis using a plane frame program, Dr. Bridge [19]. The finite-element model of the Yonghe Bridge was developed employing 34 reinforced concrete beam elements for the towers, 160 prestressed concrete beam elements for the main girder, and 88 cable elements for the cable strays (44 for the original ones and 44 for the newly replaced ones), respectively. By the way, every four cables in one pair were merged into one cable element. The influence of geometric nonlinearity due to the cable-sag effect is considered in the finite-element model by the equivalent Dischinger elastic modulus of stays [20]. Also, the shrinkage and creep effect of concrete and the relaxation effect of prestressed steel bars are taken into account by the bridge design code of China [21]. The main piers ( $P 2$ and $P 3)$ are fixed at the bottom, and the main girder is supported by four expansion bearings at the other piers ( $P 1$ and $P 4)$ and abutments (A0 and A5).Figure 12 shows a line diagram of the model geometry.

The full construction process of the bridge was simulated by the method of construction stage analysis [22, 23], including the original erection procedure and the later retrofitting process during operation (such as replacement of the closure segment, refurbishment of deck pavement, and replacement of cable stays). The initial finite-element model was first developed by performing the simulation of actual and full process of the bridge. Then, it was calibrated and corrected moderately according by the construction monitoring results, obtained during the original erection and the later retrofit, to match the measured structural indexes, including cable forces, bridge deck deflection, and tower horizontal displacements. Ultimately, a modified finite- 


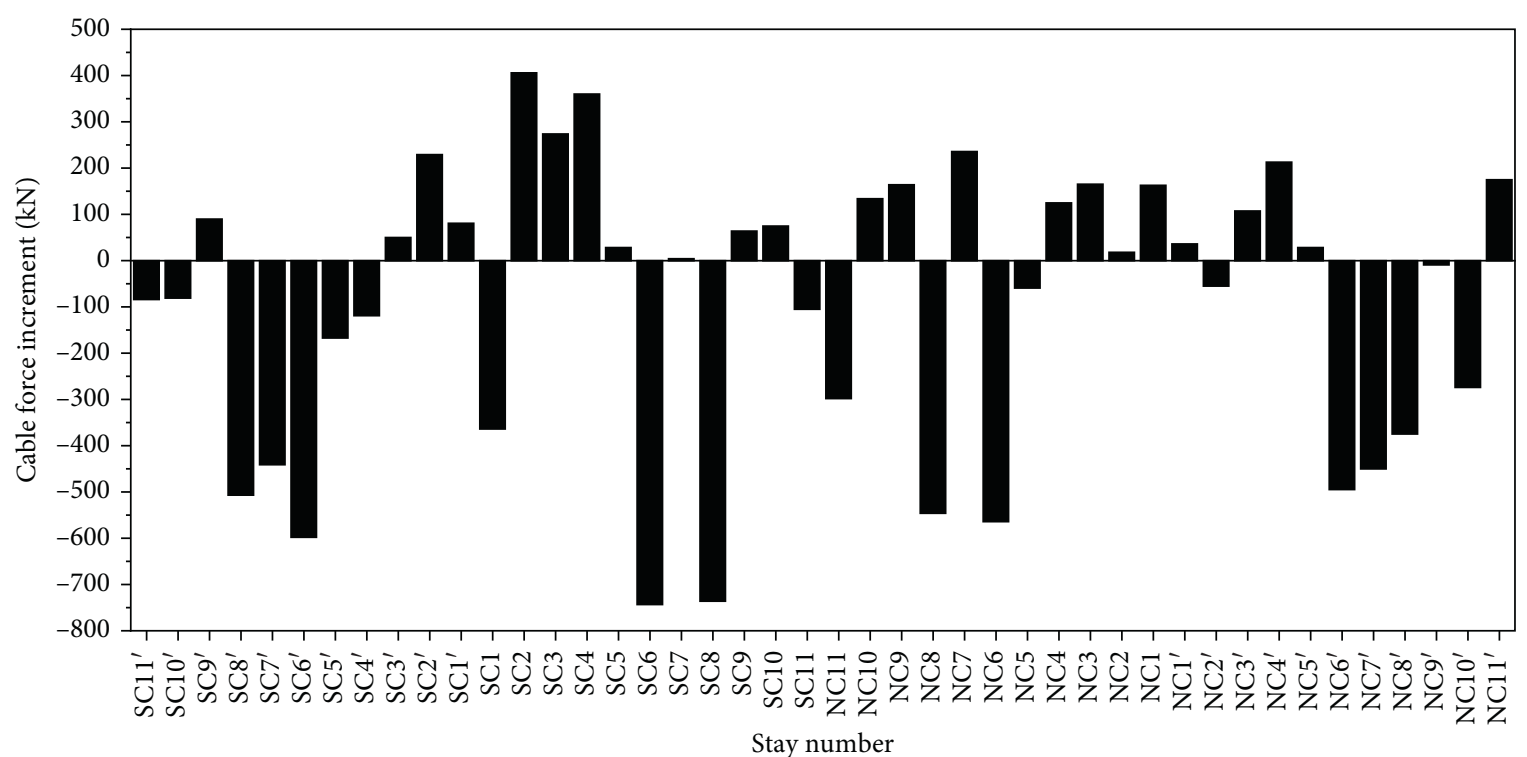

FIgUre 10: Cable force increments just after complete cable replacement.

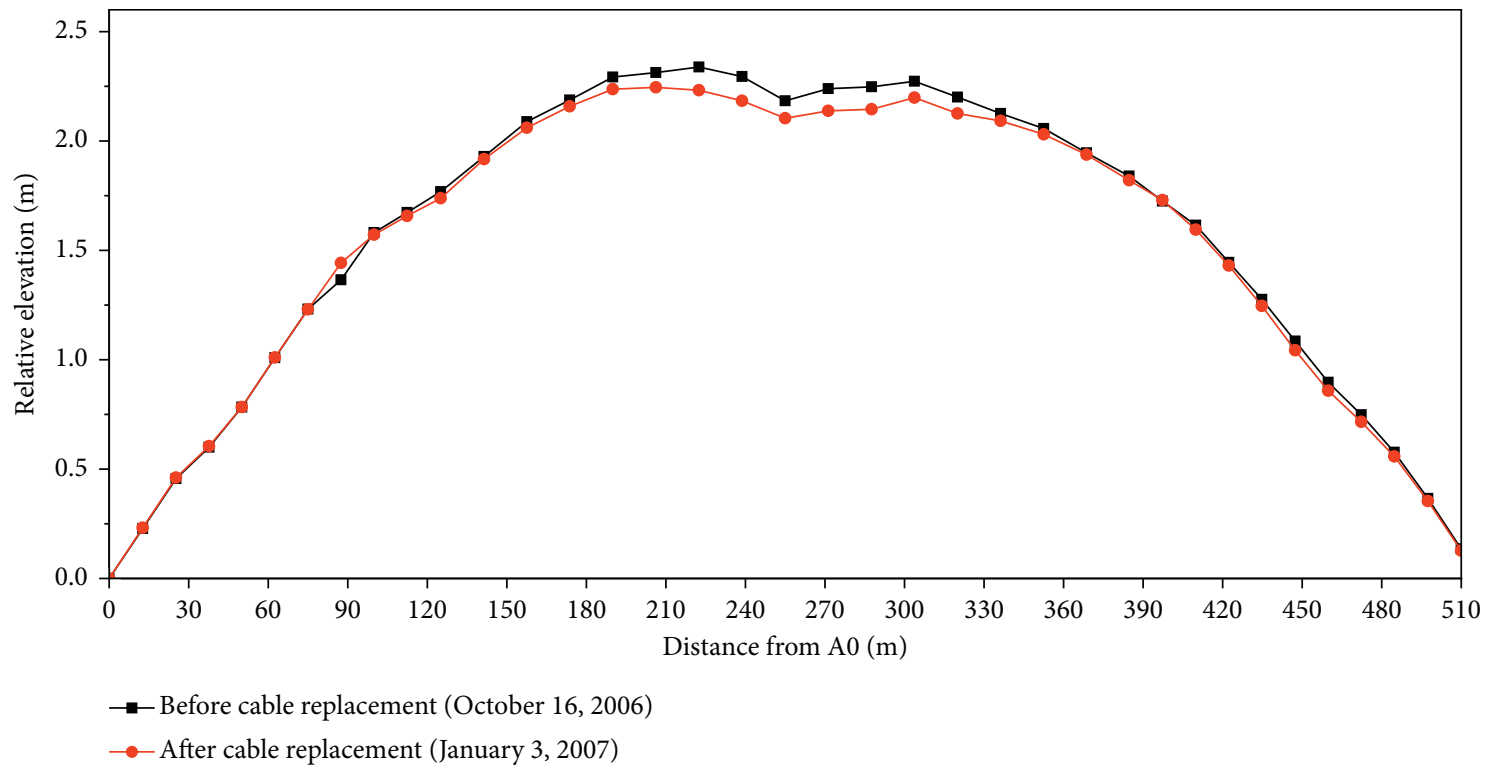

FIGURE 11: Geometry profiles of bridge deck before and after cable replacement.

element model was obtained and was used as a baseline for adjusting the tension in the new cables.

Many researchers have addressed the problem of optimization of stay forces or cable adjustments from different point of views. The proposed methodologies are generally divided into the following three categories:

(1) Making the displacements of deck or pylons due to dead load near to null, disregarding the static requirements (zero displacement approach).

(2) Reaching an approximate distribution of internal forces (such as the desired dead load bending moment in the deck), disregarding the displacement demand (static approach).
(3) Satisfying the displacement demand and the related dead load configuration (mixed approach).

Wang et al. [24] have developed the zero displacement method by a finite-element computation procedure for shape finding. In this procedure, a "shape iteration" is carried out repeatedly and ultimately a reasonable initial shape of cablestayed bridges can be easily determined under the action of dead load of girders and pretension in inclined cables.

Janjic et al. [25] proposed an approach, i.e., the socalled "unit load method" to estimate stay stresses by imposing unitary forces to achieve the desired bending moments on the deck, without considering deformation demands. This method has been successfully applied to 
cable-stayed bridges and also to arch bridges with cantilever construction supported by temporary stays [26]. Arici et al. [27] also proposed a methodology of stay stressing with the final target of reaching a continuous beam on rigid supports behavior for the dead load configuration. Some practical suggestions are given to designers, in order to minimize time-dependent effects on deck and stay internal forces and to reach an optimal final configuration. Fabbrocino et al. [28] developed a procedure for the optimization of cable forces in a composite cable-stayed bridge, aiming to achieve the desired bending moment distribution through the application of a selfequilibrated state of stress induced by optimal cable pretensioning.

Xiao et al. [29] developed the influence matrix method of cable tension optimization for long span cable-stayed bridges, considering an energetic function. In this method, the problem of cable tension optimization is transformed into a problem to solve a multiple objective function under some constraints of displacements and internal forces. Recupero and Granata [30] studied the problem of the initial cable force determination in steel cable-stayed bridges and pointed out a mixed approach which satisfies the static demands related to the stress distribution on the deck and the pylon, establishing a convenient geometric profile with an assigned precamber. Actually, this approach is a modified influence matrix method. Martins et al. [31] present a method using an entropy-based algorithm to find the cable stays prestressing forces in concrete cable-stayed bridges. In this procedure, the problem of determining the cable prestressing forces in a concrete cable-stayed bridge is formulated as a multiobjective optimization problem, limiting the displacements and stresses of deck and towers. Atmaca et al. $[32,33]$ developed a program that integrates a finiteelement analysis and a Jaya algorithm with MATLAB codes to determine the posttensioning forces of a cable-stayed bridge's stay cables. In this procedure, stay-cable stress and deck displacement are taken into account as constraints for the optimization problem.

In general, these approaches described above can be applied to determine the optimal cable tensions both erection and upon completion for a concrete cable-stayed bridge, especially suitable for the design of newly built bridges. The reason for this is that the structural state in the design stage of the newly built bridges is determined or predetermined. Also, the stressing sequences of stay cables can be adjusted at any time during construction to achieve the predefined configurations or stress conditions.

However, for the Yonghe Bridge, these approaches cannot be simply employed. Due to the complex erection process of the original bridge (for example, each stay was stressed multiple times in different phases) and various timedependent factors in its running period, the current stress or internal force condition of the bridge is very undetermined. Moreover, before cable replacement, the bridge has undergone an involved retrofitting process, mainly including replacement of the closure segment and refurbishment of the deck pavement. In other words, the structural condition of the bridge has endured a complicate transformation process.
In addition, the superimposed dead load is somewhat increased, which is induced by the refurbishment.

With these difficulties in theoretical analysis, it is almost impossible to establish a relatively satisfactory finite-element model to reflect the actual structural condition of the bridge. So a methodology called "increment control" had to be adopted as a theoretical reference for the measurements during the practical retrofitting process before cable replacement. Specifically, in the finite-element model of staged construction analysis, the variation in structural state, induced by any construction stage, was considered accurate and has a possible agreement with that measured during construction.

Based on the aforementioned considerations, the stressing sequence for cable adjustment of the Yonghe Bridge depends more on the actual response of the structure than on the finite-element simulation results. The finiteelement calculation results can be only used in the preliminary analysis, which can provide a general direction for the cable tuning. In practical, a trial-and-error procedure was presented in the cable adjustment of the Yonghe Bridge to find a relatively reasonable cable force distribution throughout the bridge, simultaneously satisfying the displacement demands of the deck and pylons. The general procedure for establishing the stressing sequences can be described in detail as follows.

Firstly, employing the baseline model and the principle of Influence Matrix Method [29], the interaction between the adjacent stay cables was systematically investigated. Specifically, each cable element was individually tensioned $100 \mathrm{kN}$, and then, the tension in all cable elements was calculated, respectively. According to the calculated results, the influence of the tensioned cable's pretension forces on the tension in other cables could be easily revealed. The analysis results showed that the influence of the tensioned cable ranged only 3 cables before and after it, respectively. So the approximate range of stay number for cable adjustment was ultimately determined.

Secondly, a preliminary adjustment scheme, i.e., the stressing forces for additional pull of cables to be adjusted, was first made according to the distribution of cable force increment shown in Figure 10. Subsequently, the scheme, actually a series of construction stages for cable adjustment, was simulated in the baselined model to obtain the structural condition after cable replacement, which is routinely characterized by tension in all cables, bridge deck deflection, and tower horizontal displacements.

Thirdly, the availability and feasibility of the preliminary scheme were evaluated by the targets of cable adjustment described above, and then, a modified adjustment scheme was made. Again, the aforementioned finite-element simulation was performed, and then, the scheme was further modified. This process was repeated until the originally established targets for cable adjustment were satisfied. It follows that it is a process of repeated simulation and stepby-step approximation. The practice of the Yonghe Bridge shows that it is easy to implement this process under existing computing means. The relatively desirable scheme for cable 


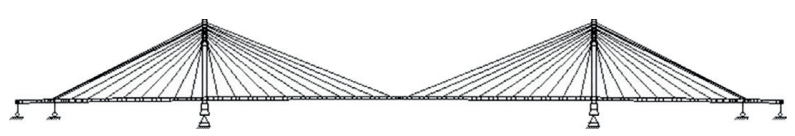

Figure 12: Plane frame finite-element model of Yonghe Bridge.

adjustment of the bridge has undergone 5 rounds of calculation and modification.

Finally, the proposed scheme based on the finite-element analysis may be corrected at any time by the actual structural response obtained by construction monitoring. Hence, the cable adjustment is a dynamic process. This is the result of many factors involved affecting the actual effectiveness of cable adjustment. Also, somewhat errors may inevitably exist between theoretical calculation and actual structural response. When the construction procedure for adjusting is multifarious, these errors may accumulate continuously and thus affect the final effectiveness of cable adjustment. So, on the completion of each cable adjustment stage, the cable forces, bridge deck profile, and tower horizontal displacements were all measured to evaluate the actual effectiveness of cable adjustment and then to provide a reference or basis for the next stage.

The final scheme for cable adjustment in the Yonghe Bridge is summarized in Table 2. The cable replacement of the bridge is comprised of 14 construction stages in sequence, and the cables to be adjusted in each stage are simultaneously stressed. As mentioned above, the adjusting force for each cable is actually an additional tensioning force on the basis of the existing cable force.

\section{Measurement-Based Structural Improvement after Cable Adjustment}

The cable replacement in the Yonghe Bridge was implemented under complete interruption to traffic. As the construction period was in winter, the complete replacement of 176 cables lasted for nearly 3 months in total, among which the cable adjustment lasted for nearly half a month. During this period, the tension in cable stays, bridge deck profile, and tower horizontal displacements were thoroughly measured.

After the completion of all the construction stages for adjustment, a relatively rational magnitude or distribution was achieved in the tension in cable stays, and correspondingly, the bridge deck profile and tower horizontal displacements were also improved significantly, compared with the condition just after cable replacement. It is indicated that the bridge possesses a reasonable structural condition after cable adjustment.

After cable adjustment, the safety factors of cable stays in the completed bridge (i.e., under the full final dead load) fell approximately between 2.6 and 3.6, which satisfied the requirements called for in the original design of the bridge (i.e., not smaller than 2.5), as shown in Figure 13. The safety factor mentioned here is the ratio of the nominal breaking force of any stay cable to its dead load pretension.

Also, the tension in most cables after adjustment was very close to the predetermined target values, and the percentage error was within the range of $\pm 5 \%$, as shown in Figure 14. A few stay cables had a slightly greater increase in tension, but the error was less than $7 \%$.

Figure 15 shows the cable force increments relative to the condition before cable replacement. It is demonstrated that the uniformity of the tension in cable stays after adjustment has been greatly improved, and the cable force distribution throughout the bridge tends to be more reasonable and satisfactory.

Figure 16 shows the measured bridge deck profile in different construction stages during cable adjustment of the Yonghe Bridge. It is demonstrated that the main span is elevated gradually with progressing in the construction phase, while an insignificant deck deflection occurred in the side spans.

For comparison, Figure 17 plots all the measured deck profiles at the key structural conditions of the bridge. It can be easily observed that cable replacement caused a significant downward deflection at its main span, thus resulting in a more notable deviation of bridge deck profile from the originally completed structure. Thereafter, a very large upward deflection occurred at the main span due to cable adjustment, which greatly improved the geometry profile of the main girder, and ultimately made it close to the originally completed condition. The fact that a small downward deflection still exists near the midspan of the main span is still the result of the time-dependent effects in the running period and a slight increase in dead load due to the retrofitting measures before cable replacement, especially the increase in the superimposed dead load induced by the refurbishment of deck pavement.

Theoretically, the local deflection near the midspan can be eliminated by increasing the amplitude of cable adjustment. However, several factors directly limit the adjustment amplitude. The cantilever splicing construction method was adopted in the erection of main girder of the Yonghe Bridge. One segment is spliced with another segment with the epoxy resin glue, followed by tensioning and lengthening of prestressed twisted steel bars. So, the working condition of the joints between the segments should be paid enough attention in the case where the bridge has been in operation for nearly 20 years. The aging of epoxy resin adhesive and the loss of prestress may worsen the stress condition of these joint sections.

Moreover, the main girder was designed as a partially PC member, and so its degree of prestress is relatively low. Thus, in the service stage, small tensile stresses may occur at the bottom flange of the sections near the midspan of the main span. Therefore, considering the stress condition of the main girder has tended to be stable over time, concrete cracking due to the excessive cable adjustment amplitude should be avoided as far as possible. 
TABLE 2: Final cable adjustment scheme in Yonghe Bridge.

\begin{tabular}{|c|c|c|c|c|c|}
\hline Construction sequence & Stay number & Cable force increment $(\mathrm{kN})$ & Construction sequence & Stay number & Cable force increment $(\mathrm{kN})$ \\
\hline \multirow{2}{*}{ Step 1} & $\mathrm{SC}^{\prime}$ & 482 & \multirow{2}{*}{ Step 8} & SC11 & 343 \\
\hline & $\mathrm{NC9}^{\prime}$ & 677 & & NC11 & 347 \\
\hline \multirow[b]{2}{*}{ Step 2} & $\mathrm{SC} 10^{\prime}$ & 605 & \multirow[b]{2}{*}{ Step 9} & SC7 & 240 \\
\hline & $\mathrm{NC} 10^{\prime}$ & 836 & & SC4 ${ }^{\prime}$ & 259 \\
\hline \multirow{2}{*}{ Step 3} & $\mathrm{SC} 11^{\prime}$ & 601 & \multirow{4}{*}{ Step 10} & SC $8^{\prime}$ & 202 \\
\hline & $\mathrm{NC}_{1}{ }^{\prime}$ & 617 & & SC8 & 266 \\
\hline \multirow{4}{*}{ Step 4} & SC8 ${ }^{\prime}$ & 735 & & NC8 & 151 \\
\hline & SC8 & 652 & & NC8 ${ }^{\prime}$ & 186 \\
\hline & NC8 & 450 & \multirow{4}{*}{ Step 11} & $\mathrm{SC} 7^{\prime}$ & 140 \\
\hline & $\mathrm{NC}^{\prime}$ & 681 & & SC9 & 229 \\
\hline \multirow{4}{*}{ Step 5} & SC6 ${ }^{\prime}$ & 700 & & NC6 & 120 \\
\hline & SC6 & 748 & & $\mathrm{NC7}^{\prime}$ & 120 \\
\hline & NC6 & 548 & \multirow{3}{*}{ Step 12} & SC6 ${ }^{\prime}$ & 150 \\
\hline & $\mathrm{NC6}^{\prime}$ & 640 & & SC6 & 150 \\
\hline \multirow{3}{*}{ Step 6} & SC7 ${ }^{\prime}$ & 595 & & $\mathrm{NC6}^{\prime}$ & 150 \\
\hline & $\mathrm{NC7}^{\prime}$ & 658 & \multirow{2}{*}{ Step 13} & $\mathrm{NC}^{\prime}$ & 184 \\
\hline & $\mathrm{SC}^{\prime}$ & 400 & & SC1 & 291 \\
\hline \multirow{3}{*}{ Step 7} & SC5 & 206 & \multirow{3}{*}{ Step 14} & \multirow{3}{*}{ SC2 } & \multirow{3}{*}{-137} \\
\hline & NC5 & 200 & & & \\
\hline & $\mathrm{NC}^{\prime}$ & 192 & & & \\
\hline
\end{tabular}

Note. A positive value shows an stressing increment, while a negative value shows a loosening increment.

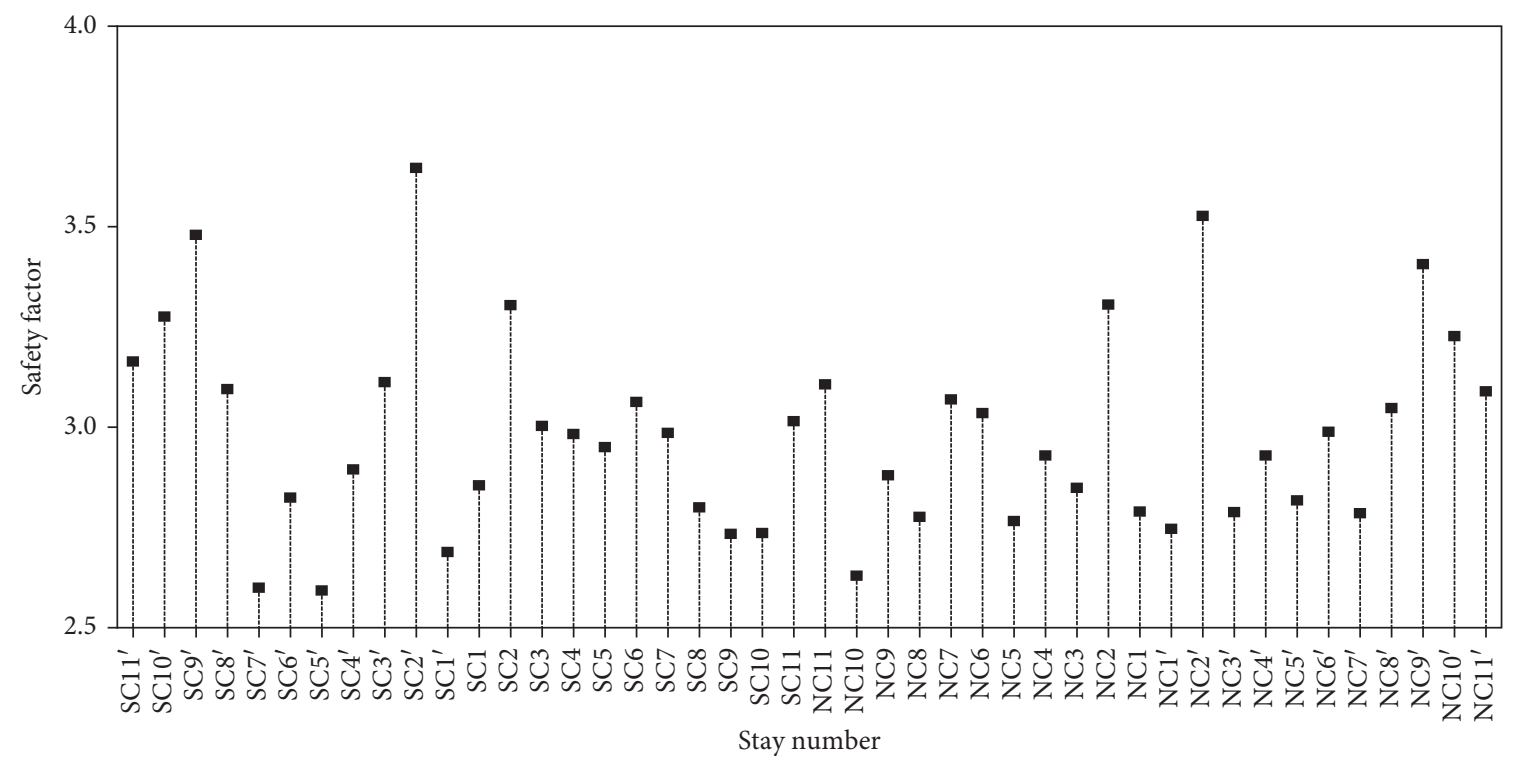

FIGURE 13: Safety factors in completed structure after cable adjustment.

In addition, an excessive adjustment amplitude may reduce the safety factor of some cable stays. Although the standard strength of the replacement cables is relatively higher, the minimum safety factor of cable stays, specified in the original design of the Yonghe Bridge, must be well satisfied, i.e., not smaller than 2.5. Actually, the development and implementation of the cable adjustment scheme in the Yonghe Bridge is precisely based on these considerations. On the whole, the cable adjustment not only alleviates the local downward deflection at the main span greatly but also makes the bridge deck profile much better than the condition before cable replacement.

After cable adjustment, the top of the south (or Tianjin) side pylon inclined longitudinally toward the main span only $26 \mathrm{~mm}$ while $5 \mathrm{~mm}$ toward the side span (or the shoreside) for the north (or Hangu) side pylon. Compared with the 


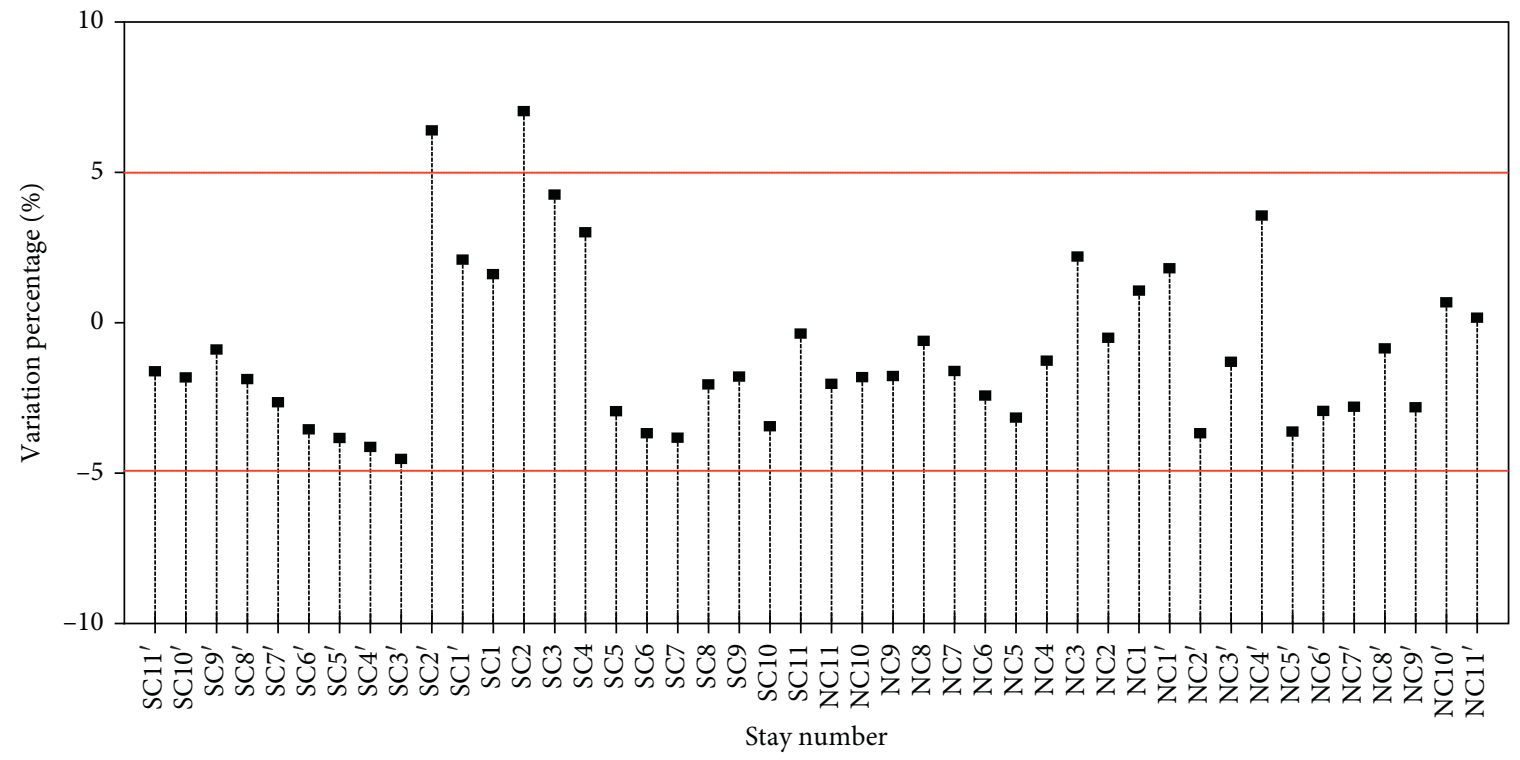

FIGURE 14: Variation in cable forces after adjustment relative to those before replacement.

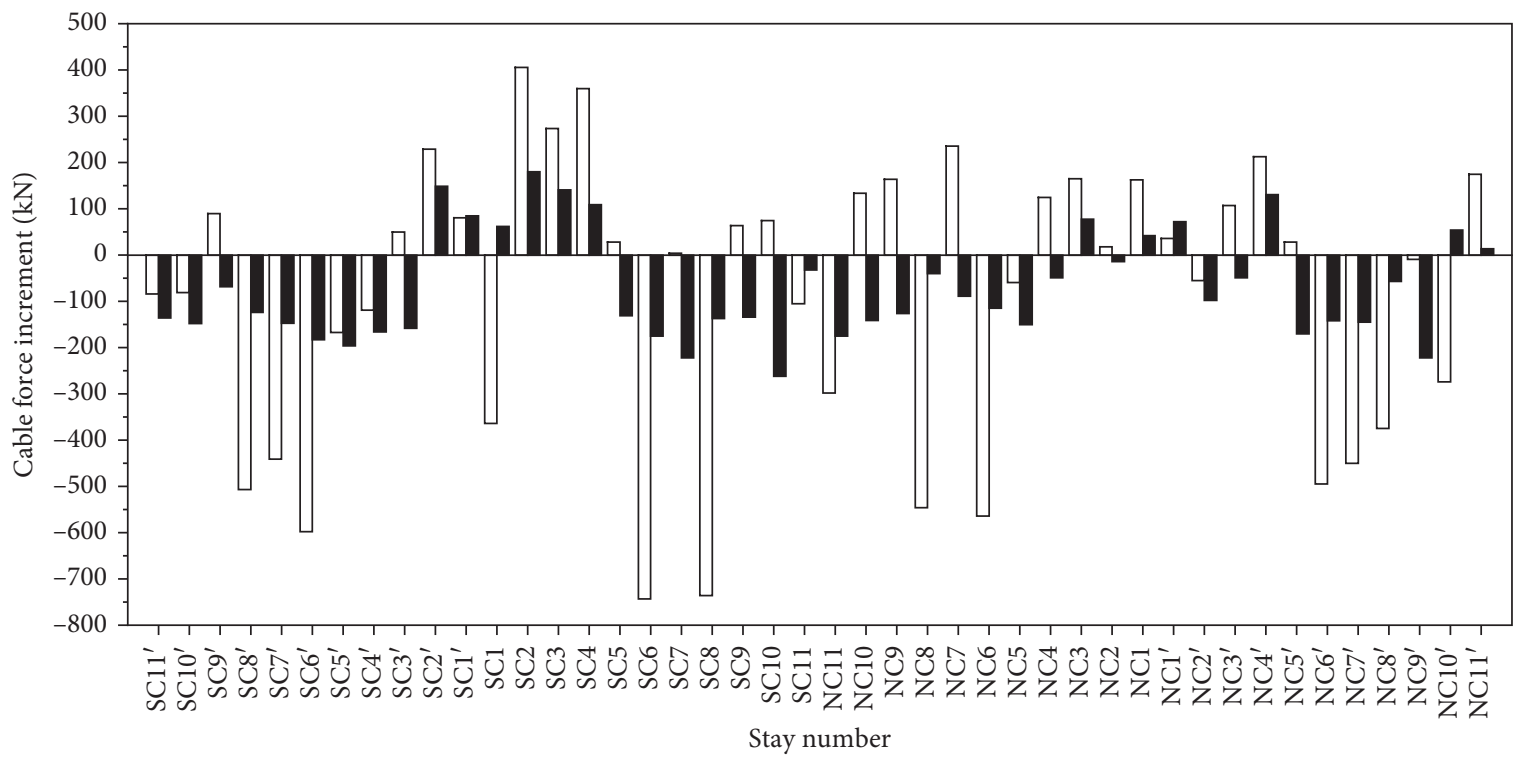

After replacement

After adjustment

Figure 15: Cable force increments after cable replacement and adjustment.

tower positions just after cable replacement, the tops of the south and north side pylons inclined toward the shoreside at the same time, with a displacement change of $33 \mathrm{~mm}$ and $63 \mathrm{~mm}$, respectively. This shows that cable adjustment has a significant influence on the towers' positions. Moreover, compared with the condition just before cable replacement, the tower positions after cable adjustment are more reasonable. Clearly, the slight inclined displacement toward the shoreside can help resist the action of live loads in the service stage and then reduce the bending moment of concrete pylon, which is beneficial to the load-carrying capacity of the bridge. 


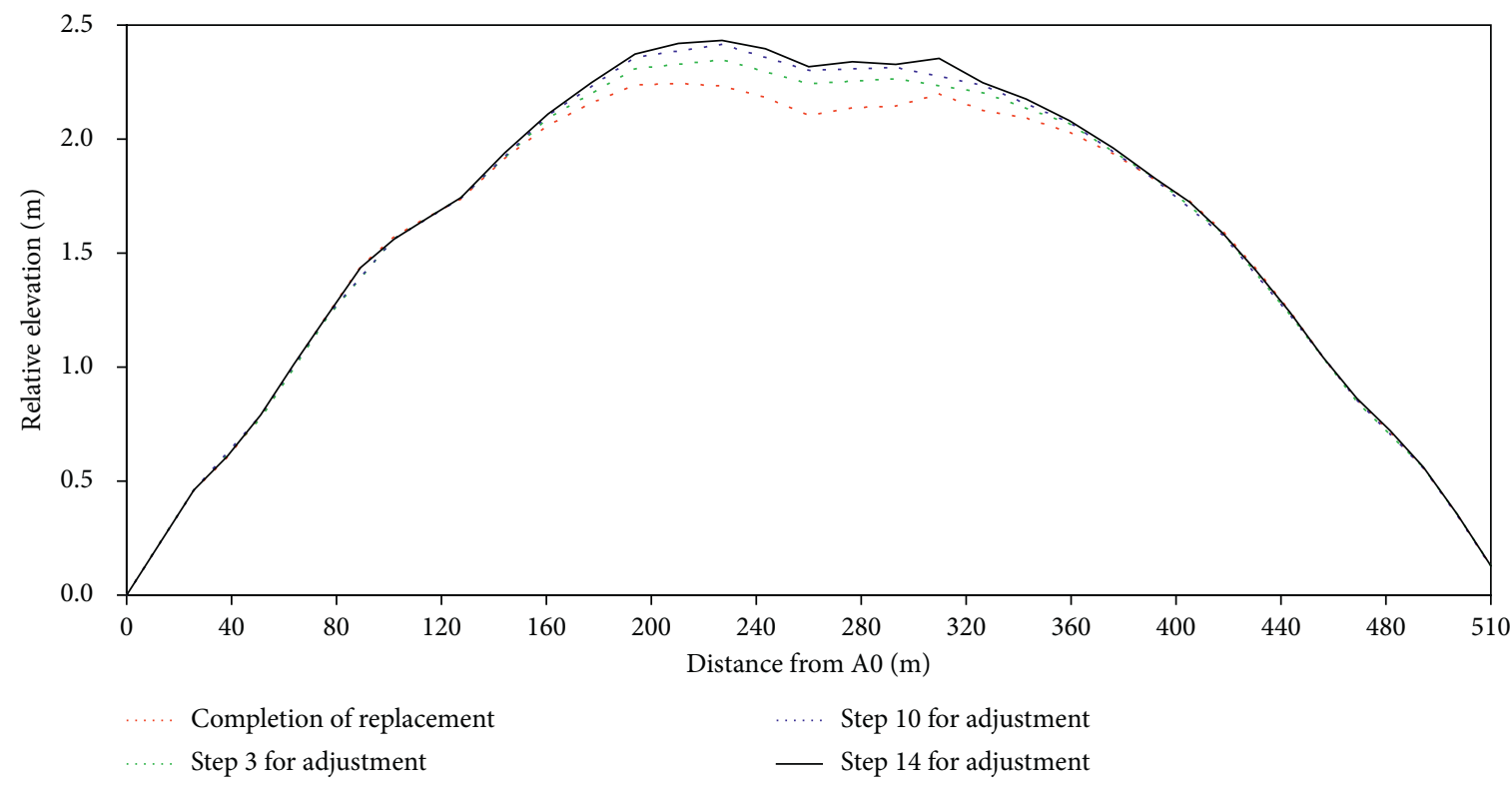

FIGURE 16: Variation in bridge deck profile with construction sequence for cable adjustment.

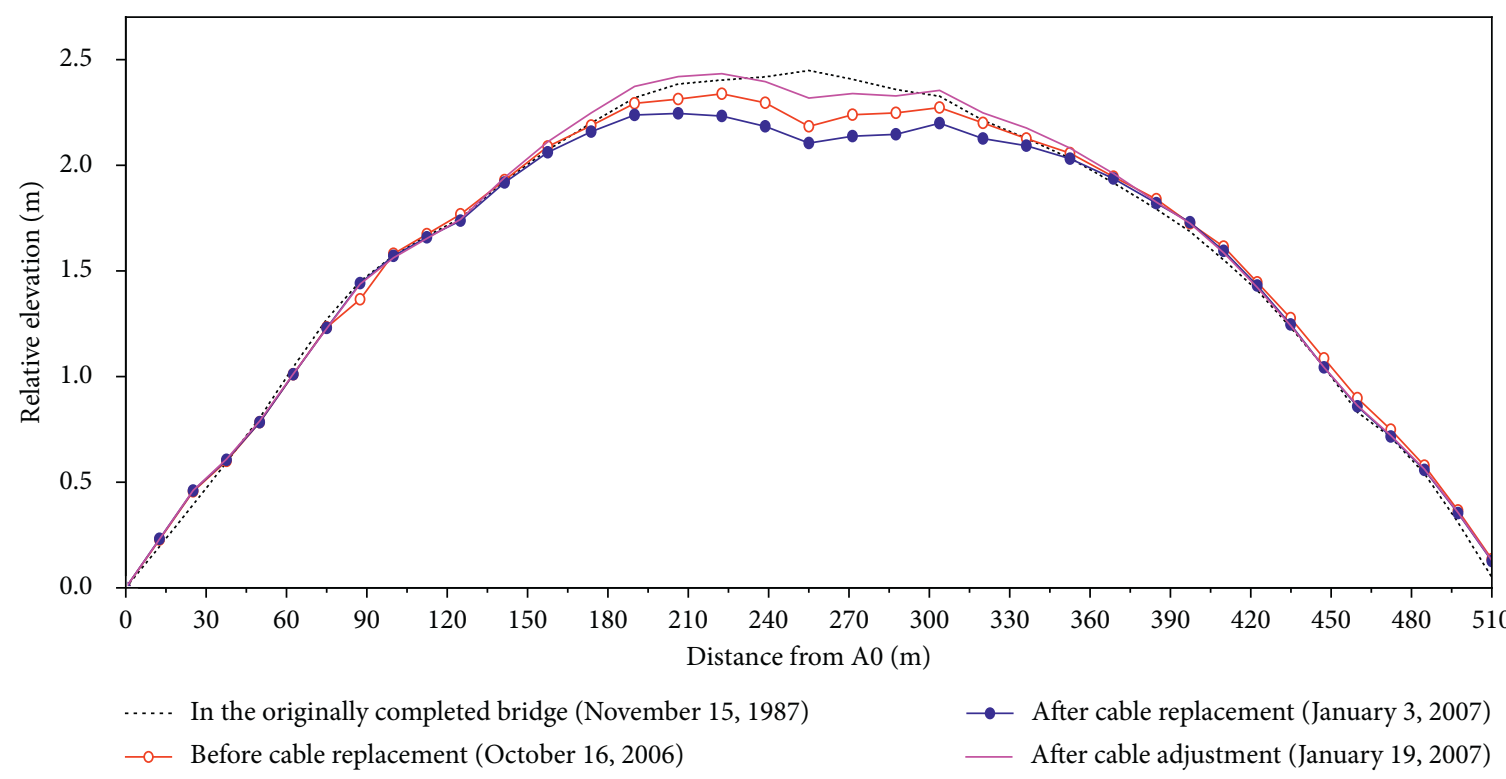

Figure 17: Measured geometry profiles of bridge deck in the Yonghe Bridge.

\section{Conclusions}

For the cable stays in a cable-stayed bridge, corrosion degradation and vibration fatigue attenuation are generally responsible for the incapability of reaching their design service life. In this instance, cable replacement is one of the most important retrofit measures ensuring the structural safety and durability. The Yonghe Bridge is a representative concrete cable-stayed bridge in China. After nearly 20 years in service-years that encompassed RCS and refurbishment of bridge deck pavement-the bridge has undergone complete replacement of its staycable system under complete traffic interruption. In this paper, the key technical details on cable replacement are systematically presented, and the following conclusions can be made:

(1) For a concrete cable-stayed bridge with a relatively long period of service and after retrofitted, the structural condition before cable replacement is generally indeterminate, and thus, the design pretension forces in new cable stays are difficult to be determined. Considering that the structural condition has tended to be stable with time, the currently measured cable forces can be adopted as an effective reference for the target pretension forces of the replacement cables. On the completion of complete 
cable replacement, the new cables may be moderately adjusted to improve the overall structural condition, which depends on the actual situation of the bridge.

(2) The control of the tensioning forces in replacement cables in construction is crucial to achieve successful completion of cable replacement in an existing cable-stayed bridge. Influenced by the construction sequences of cable replacement and the accumulated tolerances of cable forces, the magnitude and distribution of cable forces throughout the bridge will always vary to some extent just after complete replacement of its staycable system of the bridge. In this case, adjusting moderately the tension in new cables is often required, so as to attain a relatively reasonable structural condition.

(3) The adjustability of tension in cable stays is not only a characteristic but also an advantage of cable-stayed bridge. Among the concrete cablestayed bridges with the same span scale, the Yonghe Bridge has only two traffic lanes, its main girder has a relatively low flexural rigidity, and the rigidity ratio between the main girder and the pylon stem is only $1: 6$. Therefore, a prominent success has been easily achieved in improving the overall structural condition of the bridge by cable adjustment. Developing a desirable scheme for cable adjustment is often a complex process, which involves repeated calculation, comparison, and selections and also needs to take into account manifold factors. In general, it can be accomplished with the help of the plane frame finiteelement program.

(4) The cable replacement of the Yonghe Bridge has provided an exploration and demonstration for retrofitting existing cable-stayed bridges in service. In actuality, although it has some successful experiences, it also has some imperfects, especially in the aspects of precise control of cable forces and replacement construction with minimal interruption to traffic, which still need to be further studied and then put into practice.

\section{Data Availability}

The data used to support the findings of this study are available upon request to the author via hj.li@rioh.cn.

\section{Conflicts of Interest}

The author declares that there are no conflicts of interest.

\section{Acknowledgments}

The author also thanks all bridge engineers for their work in the retrofit design and field data acquisition of the Yonghe Bridge. The study presented in this paper was sponsored by the Fundamental Research Funds for the Central Public Welfare Research Institutes (Grant 2018-9021).

\section{References}

[1] A. Gu and Z. Xiang, Bridge Engineering, China Communications Press Co., Ltd, Beijing, China, 3rd edition, 2017.

[2] M. Feng, "Modern bridges in China," Structure and Infrastructure Engineering, vol. 10, no. 4, pp. 429-442, 2014.

[3] W. Podolny, W. Cox, J. Hooks et al., Performance of Concrete Segmental and Cable-Stayed Bridges in Europe, Federal Highway Administration, U.S. Department of Transportation, Washington, DC, USA, 2001.

[4] International Association for Bridge and Structural Engineering (IABSE), Case Studies of Rehabilitation, Repair, Retrofitting, and Strengthening of Structures, IABSE, Zurich, Switzerland, 2010.

[5] H. Li, "Status and development of maintenance and strengthening technologies for existing prestressed concrete cable-stayed bridges," in Proceedings of the 10th International Conference of Chinese Transportation Professionals, pp. 3670-3677, Beijing, China, August 2010.

[6] H. Li, X. Jia, and H. Jiang, "Advances in strengthening existing prestressed concrete cable-stayed bridges," in Proceedings of the 14th Chinese Overseas Transportation Association (COTA) International Conference of Transportation Professionals, pp. 896-908, Changsha, China, July 2014.

[7] A. B. Mehrabi, C. A. Ligozio, A. T. Ciolko, and S. T. Wyatt, "Evaluation, rehabilitation planning, and stay-cable replacement design for the hale boggs bridge in Luling, Louisiana," Journal of Bridge Engineering, vol. 15, no. 4, pp. 364-372, 2010.

[8] H. Li, Q. Wang, and D. Lu, "Analysis on failure mechanism of wet joints in the box girder of an existing PC cable-stayed bridge," Engineering Mechanics, vol. 29, no. Suppl. II, pp. 210-214, 2012.

[9] H. Li, W. Li, J. Zhang et al., "Rehabilitation and strengthening of Yonghe bridge in Tianjin," World Bridges, vol. 37, no. 1, pp. 53-56, 2009.

[10] H. Li, J. Zhang, W. Li et al., "Study on the technology of replacement of closure segment for strengthening existing prestressed concrete cable stayed bridges," China Civil Engineering Journal, vol. 44, no. 7, pp. 83-89, 2011.

[11] H. Li, "The current service status and maintenance advances of stay cables in prestressed concrete cable-stayed bridges," Highway Engineering, vol. 39, no. 5, pp. 165-169, 2014.

[12] Tianjin Highway Department (THD), Technical Research Report on Maintenance and Strengthening of the Yonghe Bridge, Tianjin Highway Department, Tianjin, China, 2008.

[13] N. C. Cluley and R. Shepherd, "Analysis of concrete cablestayed bridges for creep, shrinkage and relaxation effects," Computers and Structures, vol. 58, no. 2, pp. 337-350, 1996.

[14] H. Li, "Assessment of a concrete cable-stayed bridge after replacement of closure segment," Proceedings of the Institution of Civil Engineers - Forensic Engineering, vol. 172, no. 3, pp. 107-117, 2020.

[15] Standardization Administration of China (SAC), Technical Conditions for Hot-Extruding PE Protection High Strength Wire Cable of Cable-Stayed Bridge. GB/T 18365-2001, Standard Press of China, Beijing, China, 2001.

[16] H. Tabatabai, Inspection and Maintenance of Bridge Stay Cable Systems: A Synthesis of Highway Practice, Transportation Research Board, Washington, D.C, USA., 2005.

[17] H. Li, "Thermal effects in prestressed concrete cable-stayed bridge during replacement of closure segment," in Proceedings of the 19th Chinese Overseas Transportation Association (COTA) International Conference of Transportation Professionals, pp. 171-180, Nanjing, China, July 2019. 
[18] W.-X. Ren, Y.-Q. Lin, and X.-L. Peng, "Field load tests and numerical analysis of qingzhou cable-stayed bridge," Journal of Bridge Engineering, vol. 12, no. 2, pp. 261-270, 2007.

[19] Shanghai Tonghao Civil Engineering Consulting Co. Ltd. (STCEC), Dr. Bridge, User's Manual, Revision 3.0, STCEC, Shanghai, China, 2nd edition, 2006.

[20] N. J. Gimsing, Cable Supported Bridges: Concept and Design, John Wiley and Sons, Chichester, UK, 2nd. edition, 1997.

[21] Ministry of Transport of the People's Republic of China (MOT of China), Code for Design of Highway Reinforced Concrete and Prestressed Concrete Bridges and Culverts, China Communications Press, Beijing, China, 2004.

[22] B. Atmaca and S. Ates, "Construction stage analysis of threedimensional cable-stayed bridges," Steel and Composite Structures, vol. 12, no. 5, pp. 413-426, 2012.

[23] M. F. Granata, G. Longo, A. Recupero, and M. Arici, "Construction sequence analysis of long-span cable-stayed bridges," Engineering Structures, vol. 174, pp. 267-281, 2018.

[24] P. H. Wang, T. C. Tseng, and C. G. Yang, "Initial shape of cable-stayed bridges," Computers and Structures, vol. 47, no. 1, pp. 111-123, 1993.

[25] D. Janjic, M. Pircher, and H. Pircher, "Optimization of cable tensioning in cable-stayed bridges," Journal of Bridge Engineering, vol. 8, no. 3, pp. 131-137, 2003.

[26] D. Janjic, M. Pircher, and H. Pircher, "The unit load methodsome recent applications," Advances in Steel Structures (ICASS '02), vol. II, pp. 831-837, 2002.

[27] M. Arici, M. F. Granata, and A. Recupero, "The influence of time-dependent phenomena in segmental construction of concrete cable-stayed bridges," Bridge Structures, vol. 7, no. 4, pp. 125-137, 2011.

[28] F. Fabbrocino, M. Modano, I. Farina, G. Carpentieri, and F. Fraternali, "Optimal prestress design of composite cablestayed bridges," Composite Structures, vol. 169, pp. 167-172, 2017.

[29] R. Xiao, L. Jia, X. Song et al., "Influence matrix method of cable tension optimization for long-span cable-stayed bridges," in Proceedings of the IABSE Conference on CableSupported Bridges, Seoul, Korea, June 2001.

[30] A. Recupero and M. F. Granata, "A mixed approach for determination of initial cable forces in cable-stayed bridges and the parameters variability," The Baltic Journal of Road and Bridge Engineering, vol. 10, no. 2, pp. 141-150, 2015.

[31] A. M. B. Martins, L. M. C. Simoes, J. H. J. O. Negrao et al., "Optimization of cable forces on concrete cable-stayed bridges including geometrical nonlinearities," Computers and Structures, vol. 155, pp. 18-27, 2015.

[32] B. Atmaca, M. Grzywiński, M. Grzywiński, and T. Dede, "Optimization of post-tensioning forces in stay-cables of cable-stayed bridges," Budownictwo O Zoptymalizowanym Potencjale Energetycznym, vol. 8, no. 2/2019, pp. 69-76, 2019.

[33] B. Atmaca, T. Dede, and M. Grzywinski, "Optimization of cables size and prestressing force for a single pylon cablestayed bridge with Jaya algorithm," Steel and Composite Structures, vol. 34, no. 6, pp. 853-862, 2020. 